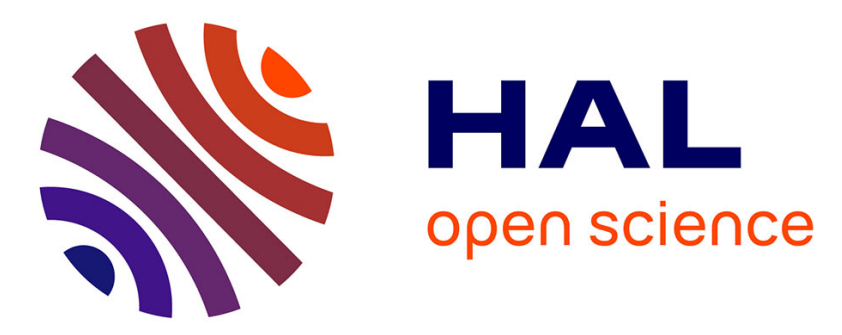

\title{
Effect of UV-aging on the mechanical and fracture behavior of low density polyethylene
}

\author{
A.K. Rodriguez, B. Mansoor, G. Ayoub, Xavier Colin, A.A. Benzerga
}

\section{To cite this version:}

A.K. Rodriguez, B. Mansoor, G. Ayoub, Xavier Colin, A.A. Benzerga. Effect of UV-aging on the mechanical and fracture behavior of low density polyethylene. Polymer Degradation and Stability, 2020, 180, pp.109185. 10.1016/j.polymdegradstab.2020.109185 . hal-03001397

\section{HAL Id: hal-03001397 https://hal.science/hal-03001397}

Submitted on 12 Nov 2020

HAL is a multi-disciplinary open access archive for the deposit and dissemination of scientific research documents, whether they are published or not. The documents may come from teaching and research institutions in France or abroad, or from public or private research centers.
L'archive ouverte pluridisciplinaire HAL, est destinée au dépôt et à la diffusion de documents scientifiques de niveau recherche, publiés ou non, émanant des établissements d'enseignement et de recherche français ou étrangers, des laboratoires publics ou privés. 


\title{
Effect of UV-aging on the mechanical and fracture behavior of low density polyethylene
}

\author{
A.K. Rodriguez ${ }^{\text {a, b }}$, B. Mansoor ${ }^{\text {a, b, *, G. Ayoub }}{ }^{\text {c }}$, X. Colin ${ }^{\text {d }}$, A.A. Benzerga ${ }^{\text {a, e }}$ \\ a Department of Materials Science \& Engineering, Texas A\&M University, College Station, TX, 77843, USA \\ ${ }^{\mathrm{b}}$ Department of Mechanical Engineering, Texas A\&M University at Qatar, Doha, 28874, Qatar \\ ${ }^{\mathrm{c}}$ Department of Industrial and Manufacturing Systems Engineering, University of Michigan, Dearborn, MI, 48128, USA \\ d ARTS ET METIERS ParisTech, 151 Boulevard de l'Hôpital, 75013, Paris, France \\ e Department of Aerospace Engineering, Texas A\&M University, College Station, TX, 77843, USA
}

Keywords:

Photo-oxidation

Mechanical behavior

Mechanical damage

Cracks

Cavitation

\begin{abstract}
A B S T R A C T
In polyethylene, a transient, oxidation-induced strengthening is often observed over a narrow range of UV radiation dose. In addition, plastic deformation may not be volume-preserving due to cavitation. Here, we employ a suite of analytical experiments and mechanical testing on pristine and oxidized lowdensity polyethylene films in order to investigate the transient strengthening behavior as well as the propensity for cavitation to fracture. Emphasis is laid on connecting macroscopically observed behavior with microscopic information involving the competition between multi-scale phenomena: chain scission and cross linking at a fine scale, chemi-crystallization, oxidation-induced cracking and mechanical damage at the meso and coarse scales. The results provide an insight into the role of cavitation in the oxidative embrittlement of semicrystalline polymers.
\end{abstract}

\section{Introduction}

Semicrystalline polymers inevitably undergo various types of aging in service. With the advent of polymers as structural materials in recent decades, understanding and predicting their response to environmental factors such as UV radiation, heat and humidity are of utmost importance. For polymers used in outdoor applications, this is of much concern considering the depletion of the stratospheric ozone and its potential consequences on aging [1]. Such is the case of the polyethylene (PE) used in pipelines, greenhouses, composites for automotive and aerospace industries, and in functional applications such as electrical insulation and thermal energy storage.

The interaction of UV radiation, in particular, with polyolefins, such as PE, causes photo-oxidative embrittlement [2,3]. Photooxidation leads predominantly to random chain scissions and, eventually to crosslinking, generally leading to a noticeable decrease in the average molecular weight, an increase in polydispersity (the

\footnotetext{
* Corresponding author. Department of Materials Science \& Engineering, Texas A\&M University, College Station, TX, 77843, USA

E-mail address: bilal.mansoor@qatar.tamu.edu (B. Mansoor).
}

distribution of molecular weight), and an increase in crosslinked structures $[4,5]$. Some studies have pointed out a relationship between the decrease in molecular weight and embrittlement [3,6], establishing a critical molecular weight $\mathrm{M}_{\mathrm{wc}} \sim 70 \mathrm{~kg} / \mathrm{mol}$ or a critical interlamellar thickness $\mathrm{l}_{\mathrm{ac}} \sim 6 \mu \mathrm{m}$ below which a sharp ductile to brittle transition occurs.

Photo-oxidation reactions are generally assumed to take place in amorphous regions where oxygen diffusion is favored relative to compact crystallites. Chain scissions may lead to chemicrystallization, a type of (low temperature) secondary crystallization $[7,8]$. Therefore, photo-oxidation may alter both the molecular weight and crystallinity of polymers, thus affecting their mechanical behavior.

Changes in the chemistry of polymers due to UV aging have previously been investigated, paying special attention to the kinetics of oxidation reactions and the formation of specific chemical groups [9-11]. On the other hand, the effects of UV aging on mechanical behavior have also been reported in the literature; for a review see Ref. [3]. Special emphasis is generally given to the characterization of oxidative embrittlement, which manifests in the decrease of the (nominal) strain to fracture with increasing oxidation.

In general, previous work has focused on either chemical or mechanical aspects of aging, but no study has examined chemo- 
mechanical aspects to sufficient extent. Fayolle et al. [6] attempted to correlate the chemical kinetics responsible for chain scissions with the decrease in strain to fracture by means of the critical molecular weight concept. However, little attention has been paid to the effect of oxidation on the strength of semicrystalline polymers, or to the chemo-mechanical aspects of oxidative embrittl ement.

That photo-oxidation may lead to transient strengthening has been reported by some authors, e.g. Ref. [12], but is left generally unexplained. The transient strengthening manifests in an increasing flow strength over a narrow range of UV doses.

On the other hand, that large plastic deformation may lead to volume change in polymers has become increasingly accepted in the literature; see Ref. $[13,14]$ for reviews. Whether the volume change is due to crazing (nanovoids with a fibrillar structure) or mere cavitation (microvoids), the outcome is dilation and pressure-sensitivity of the mechanical behavior [15]. Nano- and micro-voids have been reported in polypropylene, polyamide 6 and high density polyethylene [16-18]. However, it has been accepted so far that polymers with small crystals, such as low density polyethylene (LDPE), do not develop cavities during tensile deformation [13,16]; presumably small crystals would deform plastically before a critical stress necessary for voiding in the amorphous phase is reached. The extent to which this hypothesis holds is investigated here along with the changes in cavitation damage that occur during photo-oxidation.

In this work, we examine the transient UV-induced strengthening as well as the propensity to cavitation in pristine and oxidized semicrystalline polymer. In doing so, we analyze the relationship between macroscopically observed behavior and the competition of several microscopic phenomena: chain scission and cross linking (molecular level), chemi-crystallization (macromolecular), oxidation -induced cracking and mechanical damage (micron scale). After presenting the methods used in Section 2, the results are summarized in Section 3 with minimum discussion. The key findings are then discussed with additional analysis in Section 4.

\section{Experimental methods}

\subsection{Material}

Thin films of low density polyethylene (LDPE) were provided by Qatar Petrochemical Company (QAPCO). The material is Lotrène FB3003 produced as pellets by an autoclave high pressure process, which are then finished in an OCS cast film extruder. Unlike other grades, such as FD0374, the chosen LDPE grade is additive-free (no antioxidant, UV stabilizer, slip agent or anti-blocking agent). It is typically used in heavy-duty film applications, including for agriculture. It has a weight average molecular weight of $M_{w}=164$, $500 \mathrm{~g} / \mathrm{mol}$, a melt flow index of $0.30 \mathrm{~g} / 10 \mathrm{~min}$, and a crystalline melting point of $109^{\circ} \mathrm{C}$ according to ASTM E-794. The films were $50 \mu \mathrm{m}$ thick so as to enable nominally uniform oxidation when exposed to UV radiation.

\subsection{UV aging}

Accelerated weathering was carried out in a QUV Weathering Tester (Q-Lab Corporation). The tester had fluorescent UVA bulbs, which are able to simulate the spectral irradiance during daylight. A modified version of an ASTM G-154 standard cycle [19] was used to decouple the effect of humidity on the UV aging of LDPE (which will be studied in a follow up paper). Thus, the aging experiments were done with a radiance of $1.55 \mathrm{~W} / \mathrm{m}^{2}$ at a wavelength of $340 \mathrm{~nm}$, with no water condensation cycle. The samples were irradiated at a measured temperature of $60 \pm 2^{\circ} \mathrm{C}$ for $24,48,72,96,192$ and $240 \mathrm{~h}$. Considering that the typical UVA radiance in some regions is about
$5000 \mathrm{~kJ} / \mathrm{m}^{2}, 240 \mathrm{~h}$ of aging would correspond to a radiation received over a period of $3-4$ months.

\subsection{Fourier Transform Infrared Spectroscopy}

Fourier Transform Infrared Spectroscopy (FTIR) was used to evaluate the extent of the photo-oxidation. The IR spectra of virgin and photo-oxidized PE films were determined with a PerkinElmer Frontier device within the $4000-400 \mathrm{~cm}^{-1}$ range by averaging the 32 scans obtained with a minimal resolution of $4 \mathrm{~cm}^{-1}$. During the photo-degradation of polyethylene, carbonyl groups $(C=0)$ such as ketones, aldehydes, carboxylic acids and esters are expected to be formed [11,20]. For this, a Brucker IFS 28 IR spectrophotometer was used to follow the absorption bands of the carbonyl groups at a wavelength of $1720 \mathrm{~cm}^{-1}$ and vinyl groups at $908 \mathrm{~cm}^{-1}$ [20]. The concentrations of carbonyl and vinyl groups were calculated using the classical Beer-Lambert law:

$[$ Concentration $]=\frac{A}{b \varepsilon}$

where $A$ is the absorbance, $b$ the sample thickness and $\varepsilon$ the molar absorptivity coefficient, taken to be $405 \mathrm{lmol}^{-1} \mathrm{~cm}^{-1}$ and 122 $\mathrm{lmol}^{-1} \mathrm{~cm}^{-1}$ for carbonyl and vinyl, respectively [21].

\subsection{Differential scanning calorimetry}

To determine the crystallinity ratio and lamellar thickness, thermograms from differential scanning calorimetry (DSC) were used. The crystallinity ratio was calculated according to:

$X_{C}=\frac{\Delta H_{m}}{\Delta H_{m 0}}$

with $\Delta H_{m}$ and $\Delta H_{m 0}$ the heats of melting of the specimen and the crystal, respectively.

The lamellar thickness of crystals, $l_{c}$, was estimated using the Gibbs-Thomson equation:

$l_{c}=\frac{2 T_{m 0} W}{\rho_{c} \Delta H_{m 0}} \frac{1}{T_{m 0}-T_{m}}$

where $\rho_{c}$ is the density of the crystalline phase, $T_{m}$ is the experimental melting point, $T_{m 0}$ the equilibrium melting point, and $W$ the surface energy. The following values were taken from the literature [22] for PE: $T_{m 0}=415 \mathrm{~K}, W=70.0 \mathrm{mJm}^{-2}, \rho_{c}=1000 \mathrm{~kg} \cdot \mathrm{m}^{-3}$, and $\Delta H_{m 0}=292 \mathrm{~J} \mathrm{~g}^{-1}$. The Gibbs-Thomson equation was also used to estimate the thickness of secondary crystals assuming the same heat of melting and using corresponding measured values of $T_{m}$, as explained in context below.

\subsection{Gel permeation chromatography}

The changes in the molecular weight of PE with UV aging time were measured at $140^{\circ} \mathrm{C}$ with high temperature gel permeation chromatography (HT-GPC). Experiments were carried out with a PL-GPC 220 Agilent Technologies device equipped with a guard column, two columns branded PlGel Olexis connected in series, and three different (refractive index, viscometer and light scattering) detectors acting in concert and providing distinct but complementary information. This advanced technology allows a direct measurement of the molecular masses (without extrapolation, correction or column calibration) and degree of branching in a single experiment. The eluent was 1,2,4-trichlorobenzene (TCB) stabilized by 0.025 wt\% of 2,6-di-tert-butyl-4-methylphenol (BHT). 
It was filtered with a $1 \mu \mathrm{m}$ pore size membrane (in glass fiber) before use. The injection volume was $100 \mu \mathrm{L}$ and the flow rate was 1 $\mathrm{mL} \cdot \mathrm{min}^{-1}$. PE samples were dissolved in BHT/TCB (at a concentration of 2 g. $\left.\mathrm{L}^{-1}\right)$ at $140^{\circ} \mathrm{C}$ under stirring for $1 \mathrm{~h}$.

The weight average $\left(M_{w}\right)$ and number average $\left(M_{n}\right)$ molecular weights were calculated for each aging time. The initial weight and number average molecular weights for the LDPE films were $M_{w}=$ $164,500 \mathrm{~g} / \mathrm{mol}$ and $M_{n}=18,200 \mathrm{~g} / \mathrm{mol}$, respectively. Additionally, the polydispersity index (PDI), was calculated as:

$\mathrm{PDI}=\frac{M_{w}}{M_{n}}$

Knowing $M_{n}$ and $M_{w}$ for each aging time, the corresponding numbers of chain scissions $n$ and crosslink nodes $x$ per unit mass were deduced from Saito's equations as reported in Ref. [6]:

$\Delta_{n}=\frac{1}{M_{n}}-\frac{1}{M_{n 0}} \quad$ and $\quad \Delta_{w}=\frac{1}{M_{w}}-\frac{1}{M_{w 0}}$

$n=\frac{2}{3}\left(2 \Delta_{n}-\Delta_{w}\right)$ and $x=\frac{1}{3}\left(\Delta_{n}-2 \Delta_{w}\right)$

\subsection{Mechanical testing}

Tensile specimens of as-received and aged films were cut out using a custom-made metallic punch along the machine direction (MD). The specific geometry shown in Fig. 1 is intended to localize the deformation in the central part of the specimen [23].

Tensile tests were conducted at room temperature using an MTS Insight machine equipped with a $1 \mathrm{kN}$ load cell. A true axial strain rate of $5 \cdot 10^{-3} \mathrm{~s}$ "TT5843c571"'AD1 was imposed. To this end, the crosshead speed was adjusted with the feedback of a LX MTS laser extensometer. This implies a constant true strain rate prior to necking. The laser extensometer was also used to measure elongation, and the two dots in Fig. 1 represent the locations of the reflective tape marks. The repeatability of the mechanical response was checked by carrying out at least three, and up to six realizations of the same test condition.

Full field strain measurements were obtained using a Digital Image Correlation (DIC) setup by Dantec. Tensile specimens were painted with a black and white speckle, and the displacement of the speckle pattern was tracked during deformation using a Stingray high performance 2 Megapixel FireWire camera. Data processing was performed using the Istra4D software by Dantec.

The true (axial) stress was calculated using the formula [24]:

$\sigma=\frac{F}{S_{0}} \exp \left(-2 \bar{\varepsilon}_{11}\right)$

where $F$ is the force, $S_{0}$ is the initial cross-sectional area of the specimen, and $\bar{\varepsilon}_{11}$ constitutes direct output from the DIC software of the true strain in the transverse direction (TD) extracted at the center of the specimen; see Fig. 1. The cross-sectional area is $S=w t$ with $w$ the width and $t$ the thickness. Let $\varepsilon_{\mathrm{T}}=\ln \left(w / w_{0}\right)$ and $\varepsilon_{\mathrm{N}}=$ $\ln \left(t / t_{0}\right)$ be the transverse and normal true strains, respectively. Assuming transverse isotropy, $\varepsilon_{\mathrm{T}}=\varepsilon_{\mathrm{N}}$. Hence, $2 \varepsilon_{\mathrm{T}}=\ln \left(w / w_{0}\right)+$ $\ln \left(t / t_{0}\right)=\ln \left(S / S_{0}\right)$. Finally, equation (7) is obtained by identifying $\varepsilon_{11}$ from DIC with $\varepsilon_{\mathrm{T}}$. Note that equation (7) assumes transverse isotropy and a negligible strain gradient in the transverse direction, which are generally good assumptions, but does not assume plastic incompressibility; see Ref. [24] for details.

In addition, a limited investigation of plastic anisotropy of the as-received film was carried out using a different, simpler



Fig. 1. Tensile specimen geometry (dimensions in $\mathrm{mm}$ ). The dots mark the locations of the laser extensometer trackers.

geometry. Rectangular specimens ( $75 \mathrm{~mm}$ long; $25 \mathrm{~mm}$ wide) were cut out along both MD and TD. These tests were performed at a constant crosshead speed of $50 \mathrm{~mm} \cdot \mathrm{s}^{-1}$. The aim of this preliminary campaign was merely to check for directionality in the mechanical properties, hence the higher applied strain rates.

\subsection{Microscopy}

Two series of microscopic examinations have been performed. Film coupons were examined in scanning electron microscopy (SEM) prior to and after aging. The aim here was to detect possible "chemical damage" after oxidation. In addition, some tensile film specimens were observed post mortem for detection of "mechanical damage". For each coupon, the surface was first prepared by removing any residual paint (used for DIC) that did not come off after large stretching of the films. The excess paint was carefully removed using the rounded backend of a pair of laboratory tweezers. The paint was dry and came off rather easily. The parts that did not were left to avoid damage to the samples. Then each coupon was gold coated and observed in a FEI model Quanta 400 SEM with $15 \mathrm{kV}$ voltage and a spot size of 3.5. All observations were made in the MD-TD plane, Fig. 1.

\section{Results}

\subsection{Physico-chemical characterization}

During the photo-oxidation of polyethylene, several carbonyl groups $(\mathrm{C}=\mathrm{O})$ such as ketones, carboxylic acids, aldehydes and 
esters can be formed. Ketones can be decomposed according to the Norrish type I reaction, as shown in Fig. 2, thus leading to a chain scission. Alternatively, the photo-oxidation reaction can take another path resulting in a formation of vinyl groups via a Norrish type II reaction [25].

The oxidation kinetics is informed by the formation of carbonyl and vinyl groups. Fig. 3 suggests that there is an induction time of at least $48 \mathrm{~h}$ for the reactions to take place under the conditions of the experiments. In Fig. 3, it is clear that the initial concentration of vinyl groups is higher than that of carbonyl groups; this is expected since vinyl groups correspond to end-groups in nearly unoxidized LDPE [26].

The increasing vinyl index indicates an increase in the concentration of double bonds, which are associated with Norrish type II reactions [27], Fig. 2.

Meanwhile, the carbonyl index also increases but remains lower than the vinyl index. This indicates that during UV aging, carbonyl groups decompose via Norrish type I and type II reactions, thus generating profuse chain scissions [5].

The evolution of the weight average $\left(M_{w}\right)$ and number average $\left(M_{n}\right)$ molecular weights with UV aging time is shown in Fig. 4. The molecular weight averages were initially $M_{n}=18,200 \mathrm{~g} / \mathrm{mol}$ and $M_{w}=164,500 \mathrm{~g} / \mathrm{mol}$ then rapidly decrease with increasing aging time up to $96 \mathrm{~h}$. Between 96 and $192 \mathrm{~h}$, the molecular weight remained largely unchanged. At $192 \mathrm{~h}$ of UV exposure, both $M_{n}$ and $M_{w}$ reach a minimum, but $M_{w}$ increases thereafter.

The initial decrease in the molecular weight suggests a predominant chain scission process (presumably resulting from Norrish type I reactions) in this stage. The noticeable change of molecular weight after just $24 \mathrm{~h}$ is in contrast with the observations from FTIR, where the concentration of carbonyl and vinyl species remained unchanged after $48 \mathrm{~h}$ of UV exposure. This apparent

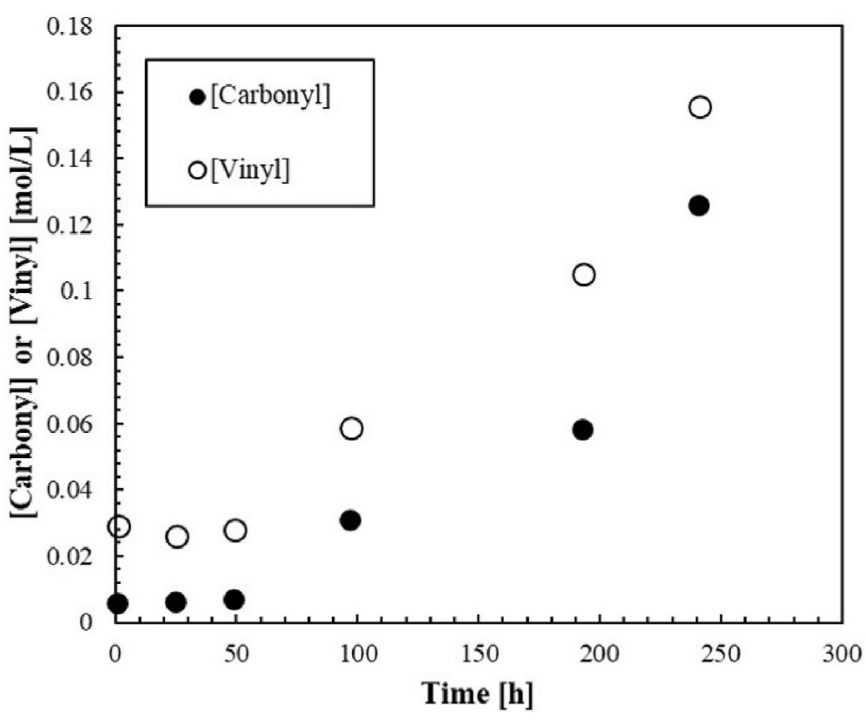

Fig. 3. Concentrations of carbonyl and vinyl groups measured by FTIR spectroscopy versus aging time.

paradox will be discussed in Section 4

It is worth noting that the PDI, which indicates the width of the molecular weight distribution, follows a trend similar to $M_{w}$, Fig. 4. The evolution of the PDI suggests a homogeneous random chain scission before $192 \mathrm{~h}$, then a prevalence of crosslinking reactions between 192 and $240 \mathrm{~h}$ of UV irradiation [6,28,29]. Indeed, if there were no crosslinking, PDI would tend towards the final value of 2 [6].

\section{Norrish type I}

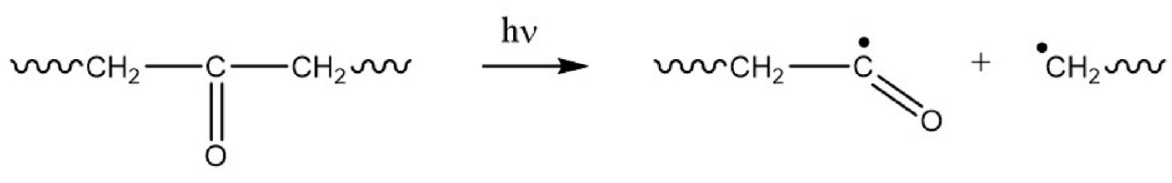

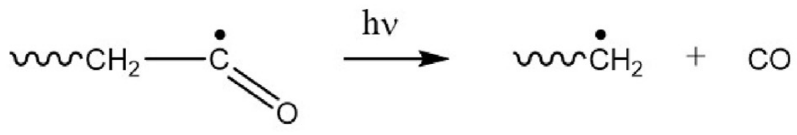

\section{Norrish type II}

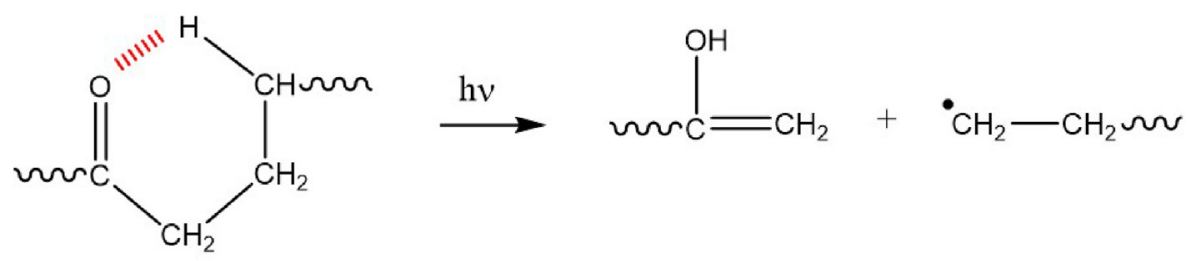<smiles>C=CCCCCCCCC(C)=O</smiles>

Fig. 2. Initiation mechanisms of photo-oxidation in polyethylene: chain scission via a free radical chain mechanism (Norrish type I); and ring decomposition mechanism (Norrish type II); adapted from Ref. [25]. 




Fig. 4. Number-average molecular weight, $M_{n}$, weight-average molecular weight, $M_{w}$, and polydispersity index (PDI), measured by GPC, versus aging time.

Fig. 5a shows the heating thermograms for the as-received and UV-aged materials, as obtained from DSC. The melting peak remains at the same temperature. However, as the aging time increases, the appearance of endothermic shoulders (circled) below the melting temperature indicates the formation of new crystallites of smaller lamellar thickness. After $24 \mathrm{~h}$ of aging, the thermogram shows that the peak melting temperature of these crystallites is below the exposure temperature $\left(60^{\circ} \mathrm{C}\right)$.

To confirm the origin of the new crystallites, we performed an additional test in which a sample was held for $24 \mathrm{~h}$ in $60^{\circ} \mathrm{C}$ in the absence of oxygen. This thermal aging (DSC not included for brevity) under vacuum resulted in the creation of some crystallites with a melting peak of $60^{\circ} \mathrm{C}$. Thus, these results indicate that the crystallites formed during photo-thermal aging at $60^{\circ} \mathrm{C}$ in air are slightly less perfect (thinner) than those formed in the absence of oxygen (thermal aging at $60^{\circ} \mathrm{C}$ under vacuum). This could be attributed to oxidation-induced defects such as hydroxyls and carbonyls, which are incorporated to the polymer chains during photo-thermal aging, thus preventing crystallization. But this could also be attributed to crosslinking induced by oxidation.

The concurrency in chain scission and crosslinking processes (evidenced in the molecular weight results discussed previously) makes the analysis of crystallinity more complicated. Oxidationinduced chain scissions can promote chemi-crystallization, a process in which the resulting shorter polymer chains can more easily reorganize and crystallize [3], presumably around pre-existing crystallite seeds in the amorphous phase, that are too small to be initially detected by DSC. At the same time, the concurrent crosslinking prevents crystallization. As the UV exposure time increases, the melting peak of these secondary crystals increases, moving towards the main melting peak, and additional endothermic shoulders appear as well. These might indicate the increasing contribution of oxidation-induced chain scissions to secondary crystallization upon aging.

In spite of the changes described above, the variation in the overall percent crystallinity with UV aging were rather small ( $\sim$ $6 \%$ ), as can be seen in Fig. 5b, indicating that the formation of the thin crystallites has a low impact on the bulk percent crystallinity of the material. However, if these thin crystallites are homogeneously distributed into the LDPE matrix, they could play the same role as crosslinks, thus affecting the mechanical behavior of LDPE. The thickness of these secondary crystallites was estimated using the Gibbs-Thomson equation (Eq. (3)) and the results are shown in Fig. 6. It is found indeed that the thickness of secondary crystallites

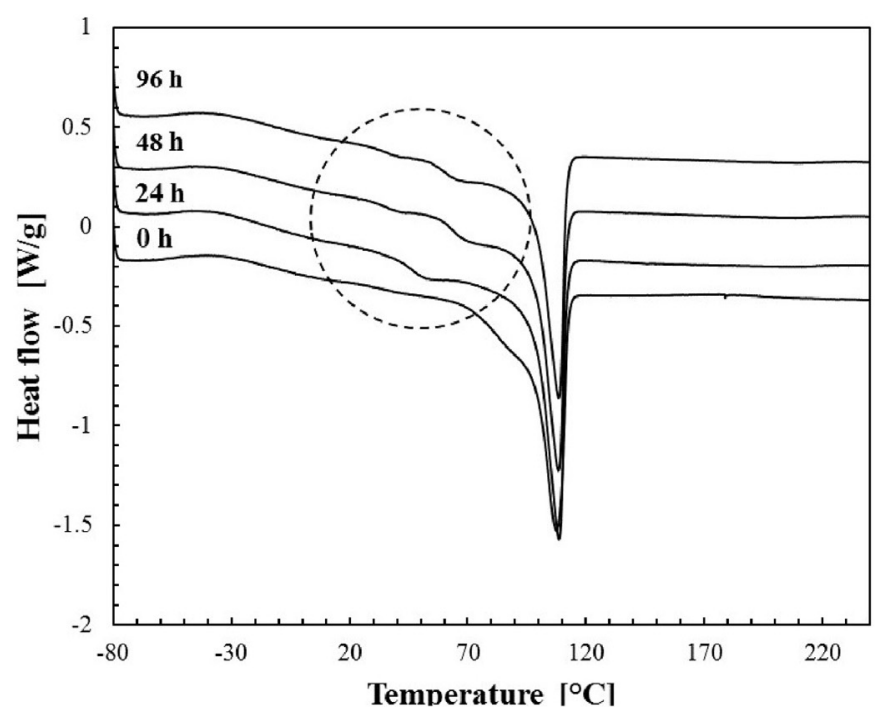

(a)



(b)

Fig. 5. (a) Heating thermograms of LDPE for various UV aging times, showing the appearance of small crystallites (circled). (b) The overall percent crystallinity versus aging time.

rapidly increases at intermediate UV aging doses. This finding is key to explaining the transient strengthening reported in the following section and discussed further below.

\subsection{Mechanical behavior}

Typical nominal stress-strain curves for the as-received and UVaged films are shown in Fig. 7a. Specimens cut out of films that were aged up to 192 and $240 \mathrm{~h}$ were too brittle to test, as they prematurely broke during setup, even with most delicate handling. For the as-received film $(0 \mathrm{~h})$ the response exhibits a peak load corresponding to neck initiation, followed by a quasi-plateau indicative of neck propagation. At large stretches, the load begins to increase again due to entropic hardening.

UV aging results in three main changes in the tensile response: (i) a steady reduction in the elongation to fracture; (ii) a transient increase in the flow stress; and (iii) a transient increase in strain hardening. In particular, the elongation to fracture is reduced by 




Fig. 6. Lamellar thickness of primary and secondary crystals versus aging time; see equation (3).

more than $50 \%$ after just $24 \mathrm{~h}$ of UV exposure. This trend, which is consistent with the literature $[3,4,6,30]$, is associated with oxidation-induced chain scission. Note that the elongation to fracture in the $96 \mathrm{~h}$ specimen is about 1.0, which means that a significant ductility is retained up to this exposure time.

The effect of UV aging on the flow stress of the material is, however, more complex. The true stress-strain responses obtained as explained in Section 2.6 are shown in Fig. 7b. Only strains up to 0.8 are shown, as the pattern distortions at large stretches impeded accurate measurements of local strains. The true stress-strain curves show larger values of stress beyond yielding, due to strain localization. Both the nominal and true responses in Fig. 7 reveal a transient strengthening at low UV doses. More importantly, the true stress-strain curves show that the strain hardening rate follows the same trend as the flow stress: it increases with UV aging up to $48 \mathrm{~h}$, and decreases at higher UV exposure times.

To better document the above trends, Fig. 8a reports the nominal stress $F / A_{0}$ at a strain $\Delta L / L_{0}=0.5$. The stress reaches a maximum between 24 and $48 \mathrm{~h}$ of UV exposure before it decays, suggesting a competition between the various reactions and processes involved in the aging of the polymer. Fig. $8 \mathrm{~b}$ displays the true stress $\sigma_{0.5}$ at a true strain $\varepsilon=0.5$. When the true stress is considered, the strengthening at intermediate aging times is even more important, with $\sigma_{0.5}$ exceeding $20 \mathrm{MPa}$ for 24 and $48 \mathrm{~h}$. Additionally, Fig. $8 \mathrm{~b}$ shows that even if the initial apparent yield is higher in the $96 \mathrm{~h}$ condition (than it is in the $72 \mathrm{~h}$ condition), the material degrades further upon straining beyond $\varepsilon \geq 0.5$, with $\sigma$ reaching values below those of the $72 \mathrm{~h}$ condition.

\subsection{Damage mechanisms}

The nominally smooth surface of a film becomes increasingly wrinkled with increasing UV radiation dose. Wrinkling is barely detectable in the $48 \mathrm{~h}$ and $96 \mathrm{~h}$ films, but becomes visible in SEM after 192 h (Fig. 9a). Eventually, superficial cracking occurs after sufficient radiation, as becomes visible in the $240 \mathrm{~h}$ film (Fig. 9b). A network of parallel microcracks is seen to have formed in these films, which explains their extreme brittleness (recall that the $240 \mathrm{~h}$ films were not mechanically "testable" as they broke while being mounted in the grips).

The largest microcracks are 100-200 $\mu \mathrm{m}$ long and oriented

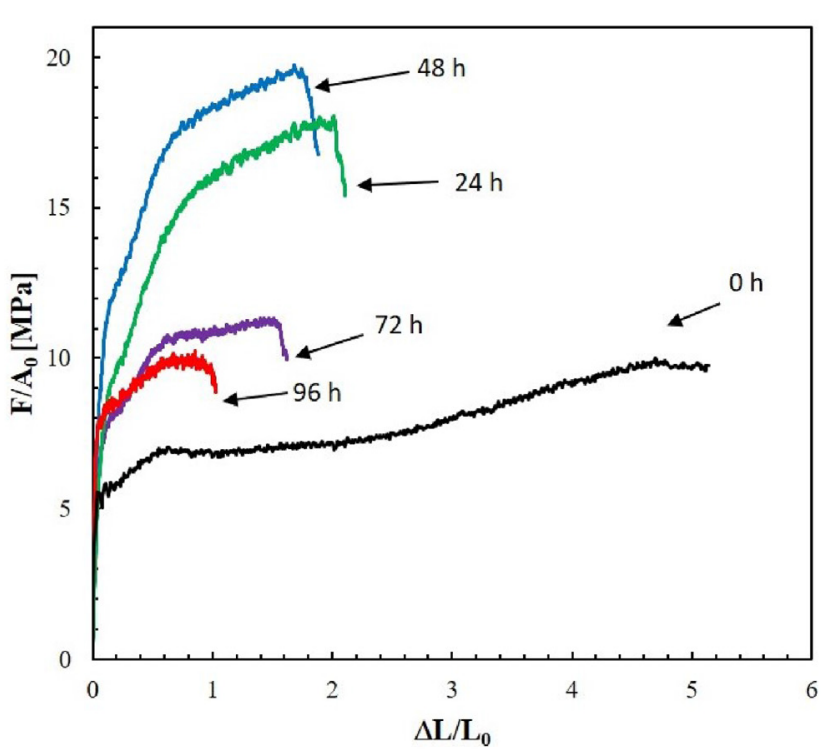

(a)

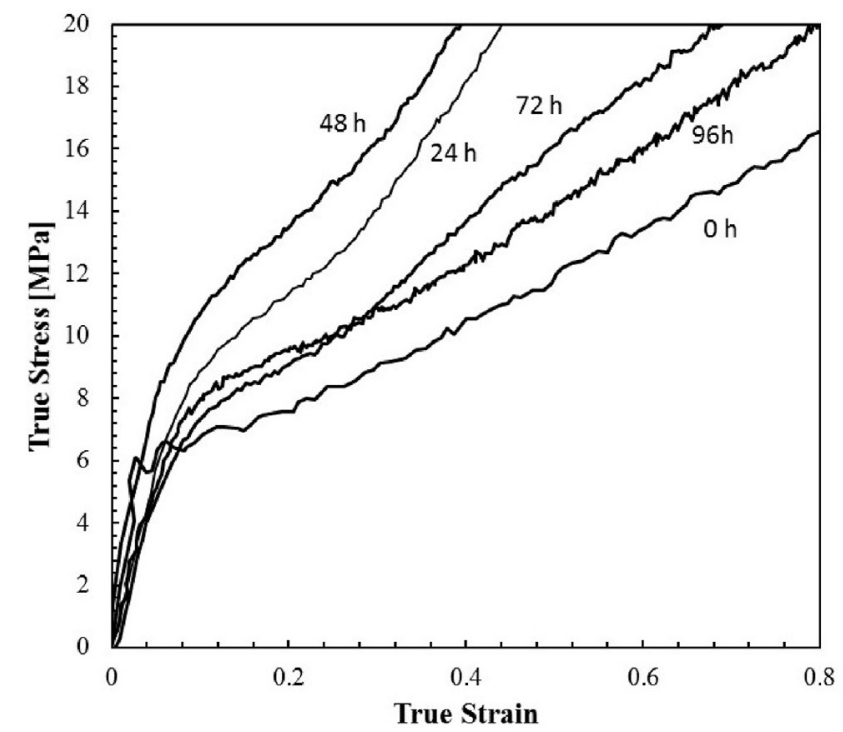

(b)

Fig. 7. (a) Engineering stress-strain curves for LDPE films UV-aged at various exposure times and tested at room temperature and a true axial strain rate of $0.005 \mathrm{~s}^{-1}$. (b) Corresponding true stress-strain curves.

along the transverse direction TD. The crack pattern is believed to stem from the film's in-plane anisotropy, which is processing induced, Fig. 9c. The MD oriented specimens exhibit higher flow stress and strain hardening rate, as well as lower strain to fracture in comparison with TD oriented specimens. This point merits further discussion in Section 4.

Recall that the tests reported in Fig. 9c were carried out at a much higher strain rate than those reported above. This explains the different stress levels and elongations to fracture.

Further details at increasingly higher resolution are provided in Fig. 10 for the film after 240 h of UV aging. Parallel microcracks, about $200 \mu \mathrm{m}$ long, can be seen in Fig. 10a. The cracks do not traverse the full thickness and appear to wedge into the film. Also, note that the film's surface is rather smooth near cracks. This is likely due to stress relief after cracking.

Away from regions with high density of such cracks, surface 

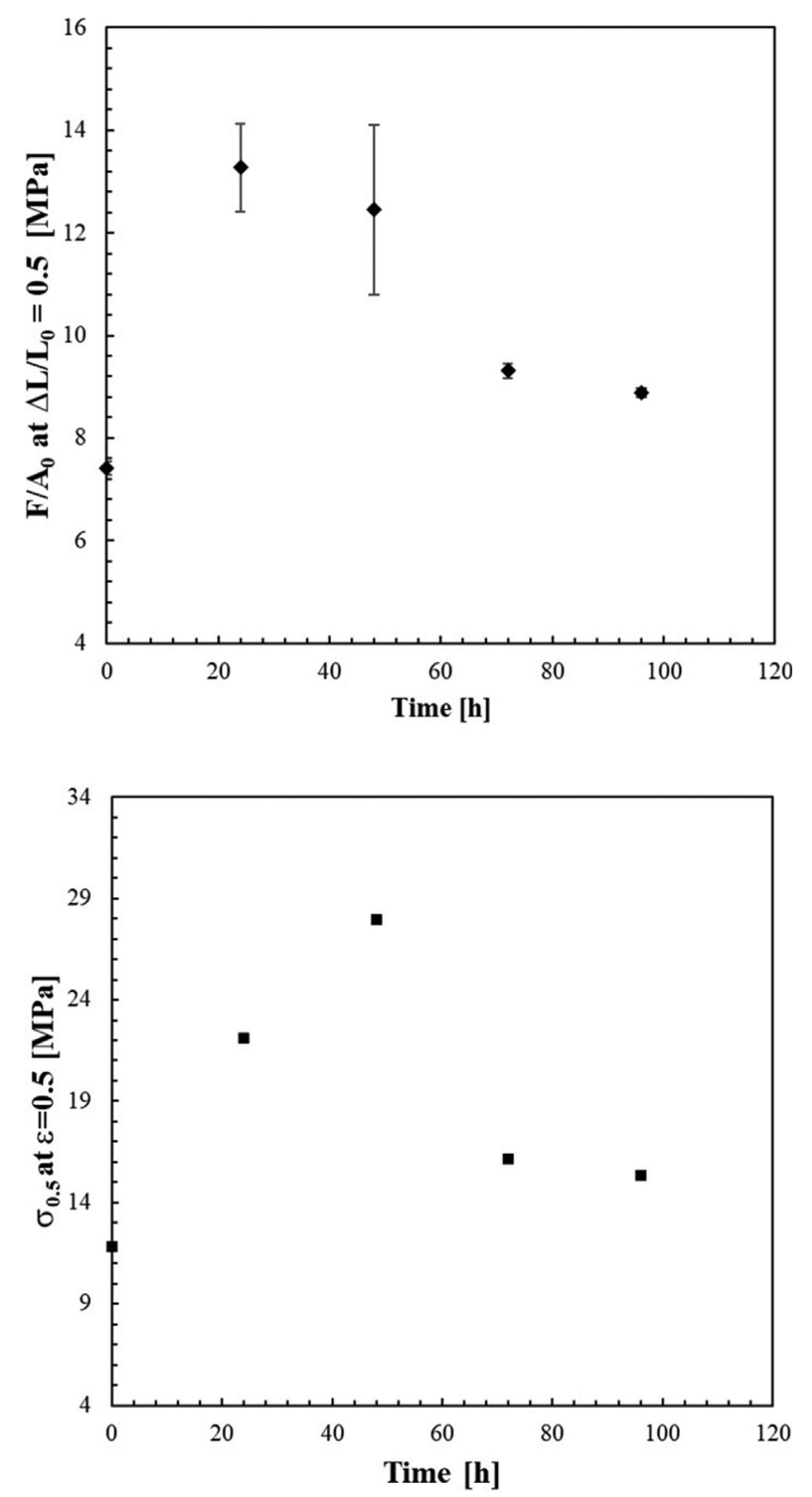

Fig. 8. Transient strengthening in the photo-oxidation of LDPE films. (a) $F / A_{0}$ at $\Delta L /$ $L_{0}=0.5$ versus aging time; and (b) flow stress at $\varepsilon=0.5, \sigma_{0.5}$ versus aging time.

wrinkling is observed, Fig. 10b. It is believed that some extent of wrinkling is seen in all aged films at various degrees. Eventually, nascent microcracks nucleate at an apex of a wrinkle, as illustrated in Fig. 10c. The nascent crack has more roughness along TD than the fully developed crack (compare Fig. 10c with Fig. 10a).

The damage observed in Figs. 9 and 10 was generated by mere UV irradiation, that is prior to any mechanical loading. A rationale for this "chemical damage" will be provided further below.

In what follows, focus is laid on post mortem fractography in mechanically loaded specimens. In general, just like in metals, two modes of fracture may occur, separately or concurrently [31]: failure by instability (slant mode) or failure by void coalescence (overall flat mode). Slant fracture was observed in all film specimens, aged or unaged, as illustrated in Fig. 11 (note the residual DIC paint in (b); see Section 2.7). The slant mode of fracture suggests that failure occurs by plastic instability, namely that the terminal event is a (macroscopic) shear band.



(a) 192 hours

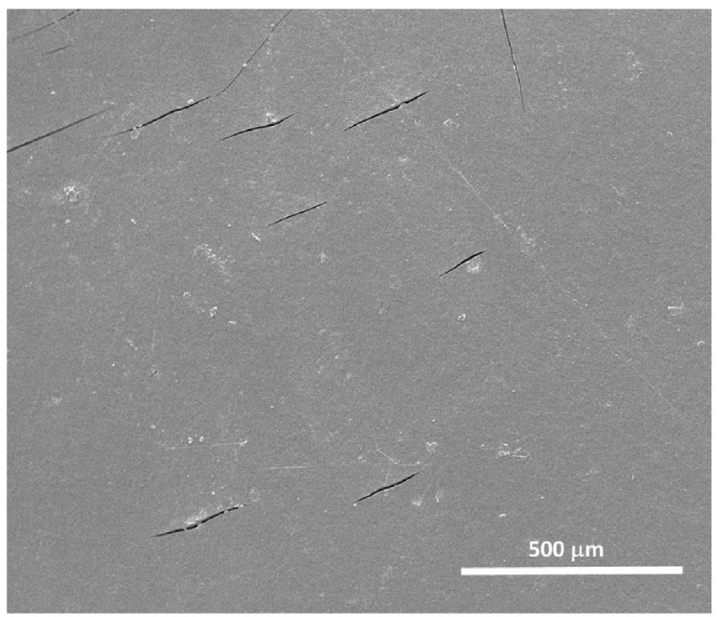

(b) 240 hours



(c) Film anisotropy

Fig. 9. SEM observations of "chemical damage" (a) $192 \mathrm{~h}$ film; (b) $240 \mathrm{~h}$ film (cracks oriented along TD). (c) Nominal stress-strain curves for MD and TD rectangular specimens. 


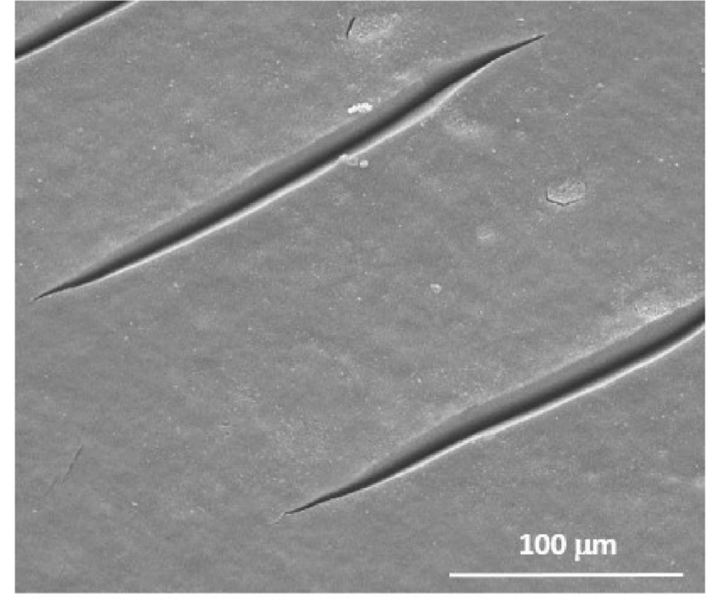

(a)

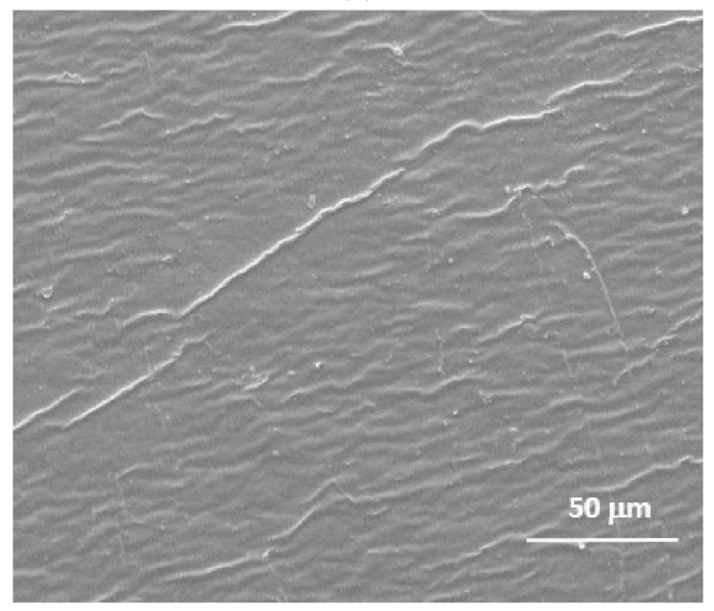

(b)



(c)

Fig. 10. Observations of chemical damage at higher resolutions after $240 \mathrm{~h}$ of UV aging: (a) Well-developed parallel cracks; (b) Surface wrinkling; and (c) Nascent microcrack. All features are perpendicular to the machine direction MD.

In the unaged specimen (Fig. 11a) there was no indication of damage beneath the fracture surface. On the other hand, aged specimens exhibited various sorts of cavitation-mediated damage. First, consider the $48 \mathrm{~h}$ aged film of Fig. 11b. Further fractographic details are provided in Fig. 12. Elongated void-like features are

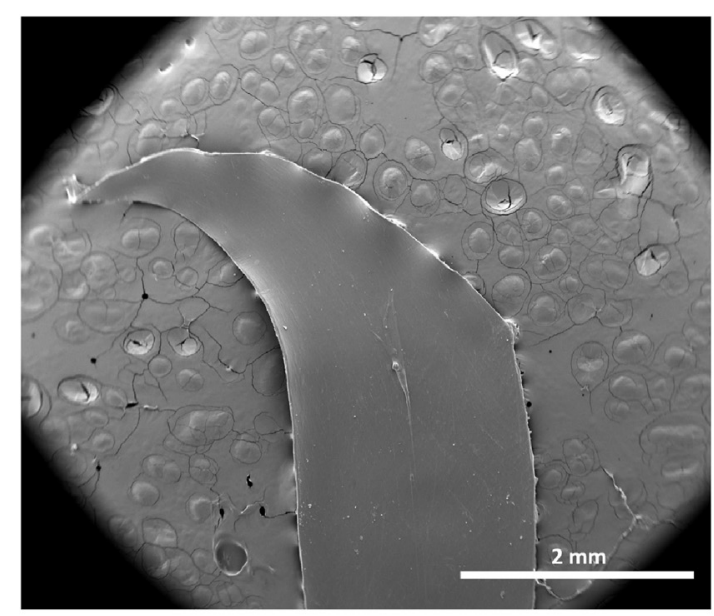

(a) 0 hours

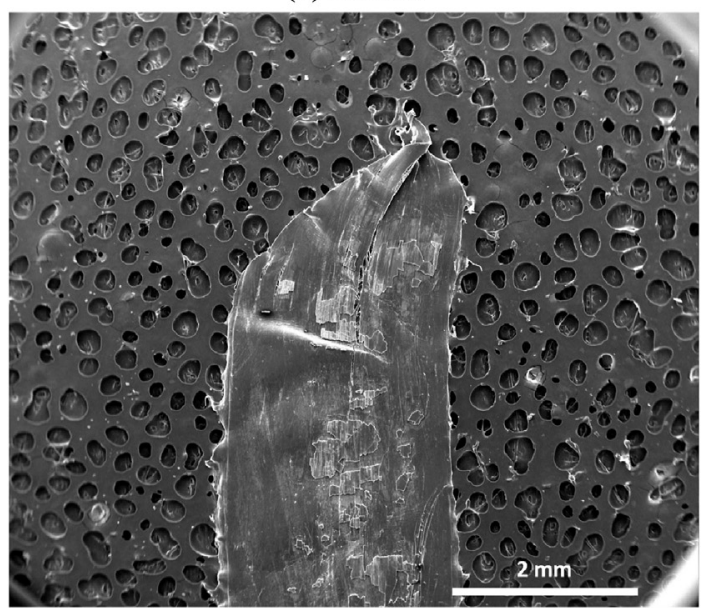

(b) 48 hours

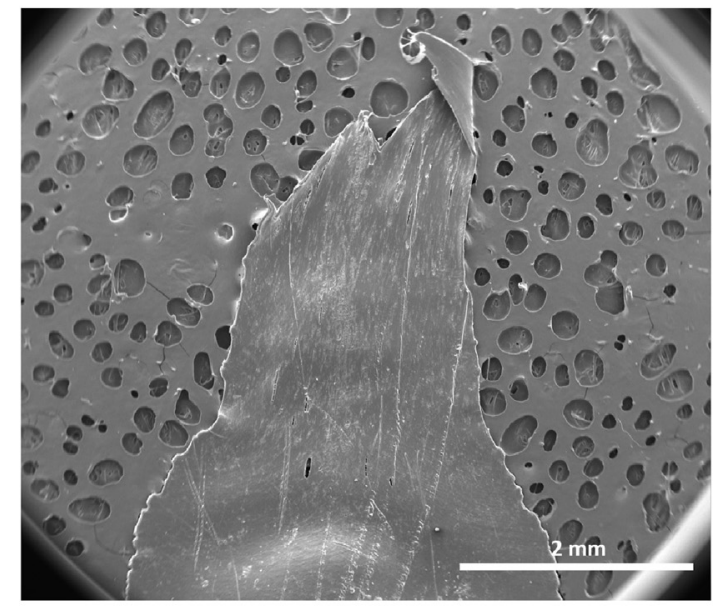

(c) 96 hours

Fig. 11. Overall fracture mode in tension of LDPE films: (a) pristine material; (b) after $48 \mathrm{~h}$ of UV aging; and (c) after $96 \mathrm{~h}$ of UV aging.

found to form parallel to the tensile MD orientation, Fig. 12b. The propensity for these voids is higher in the central region of the specimen where the necking-induced hydrostatic tension is highest, at least before complete drawing. These elongated voids coalesce in the direction of loading to form very long cracks (the central one is over $2 \mathrm{~mm}$ long), possibly leading to splitting (see Fig. 12a). 
The voids have an internal structure reminiscent of crazing with lateral void surfaces constrained by residual fibrils that do not fully break, Fig. 12c. The thickness of the fibrillar ligaments in Fig. 12c is between 3 and $5 \mu \mathrm{m}$, comparable with measurements reported elsewhere for bulk unaged polyamide 6 [17]. At a much lower scale (Fig. 12d), even smaller voids are observed in the vicinity of big ones. The small voids appear as precursors to the bigger craze-like voids and suggest a continuous damage process.

Next, consider the $96 \mathrm{~h}$ aged film of Fig. 11c with details as provided in Fig. 13. A more evident combination of mechanical damage and chemical degradation may be observed in this specimen. Just like in the $48 \mathrm{~h}$ exposed film, elongated voids are observed at a higher density, although individual voids may be shorter. A direct comparison of void sizes would be difficult since the strains to break for these two conditions are different: $\varepsilon_{b}=1.95$ versus $\varepsilon_{b}=1.47$ for the $48 \mathrm{~h}$ and $96 \mathrm{~h}$ conditions, respectively. Also, the voids are spread all over the specimen and not highly concentrated in the central region. Furthermore, traces of such elongated voids are seen deep below the fracture surface, Fig. 13b.

In some isolated areas, a different type of damage is observed, as illustrated in Fig. 13c. This type has previously been reported for various semicrystalline polymers [32]. It suggests an advanced stage of surface degradation and it is not possible to apportion the chemical and mechanical contributions in reconstructing the genesis of the stage shown in Fig. 13c. Some details elsewhere do exhibit some of the elongated voids but with more lateral opening, Fig. 13d; also note the large void at the bottom of Fig. 13b.

The reported observations of both chemical damage and (chemo-)mechanical damage are quite complex. Some discussion of that is included in the following section.

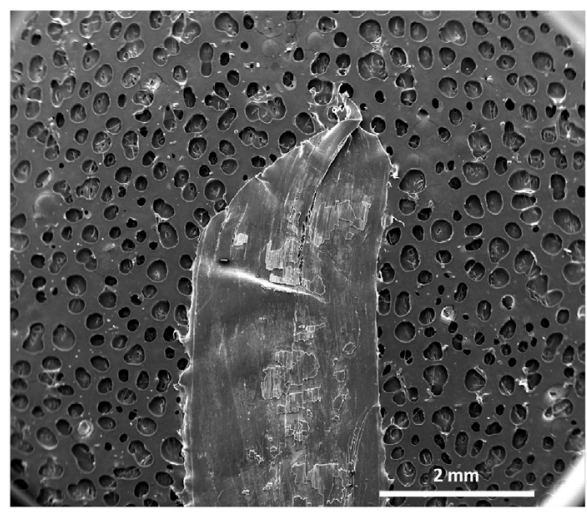

(a)

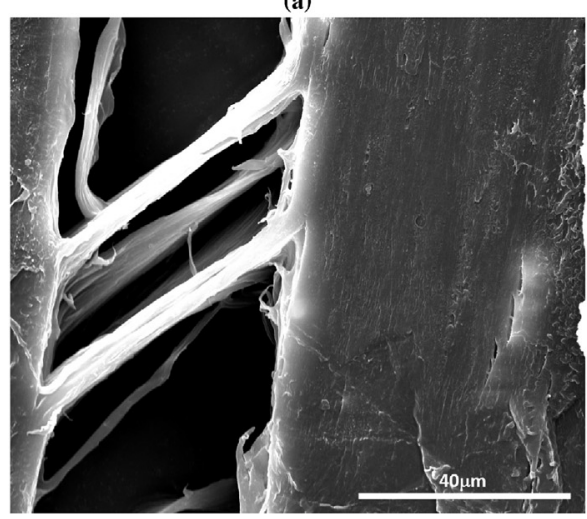

(c)

\section{Discussion}

The key findings reported above are: (i) the oxidation-induced transient strengthening (Fig. 8); (ii) the indirect evidence of secondary crystals formed because of UV aging (Fig. 6); (iii) the observation of "chemical damage" prior to any mechanical testing (Fig. 10); and (iv) the oxidation-induced cavitation upon mechanical loading (Figs. 12 and 13). Here, we discuss these findings in light of the state of the art, laying emphasis on aspects that remain largely unexplained in the literature and pointing, where appropriate, to further avenues of investigation.

\subsection{Chain scission versus cross-linking}

The loss of ductility induced by UV aging is evident in Fig. 7a. This loss is quantified in Fig. 14 in terms of a nominal strain to break, $\varepsilon_{\mathrm{b}}=\Delta L /\left.L_{0}\right|_{\mathrm{b}}$, and a true strain to fracture, $\varepsilon_{\mathrm{f}}=2 \ln \left(w_{0} / w_{\mathrm{f}}\right)$, measured post mortem ( $\sim$ one month) based on width reduction. In all conditions, $\varepsilon_{b}>\varepsilon_{\mathrm{f}}$ due to significant strain recovery after unloading and viscous effects.

The trend of a decreasing strain to fracture indicates profuse chain scission events. It is consistent with the increase in carbonyl index (Fig. 3) and decrease in molecular weight (Fig. 4). On the other hand, chain scission alone cannot explain the oxidationinduced strengthening of the polymer in the early stages of exposure to UV radiation (Fig. 8). To explain this transient strengthening some other mechanism must be invoked.

The transient behavior suggests a competition among the various radiation-mediated mechanisms, but their interplay is rather intricate. Indeed, the molecular weight decreases from the

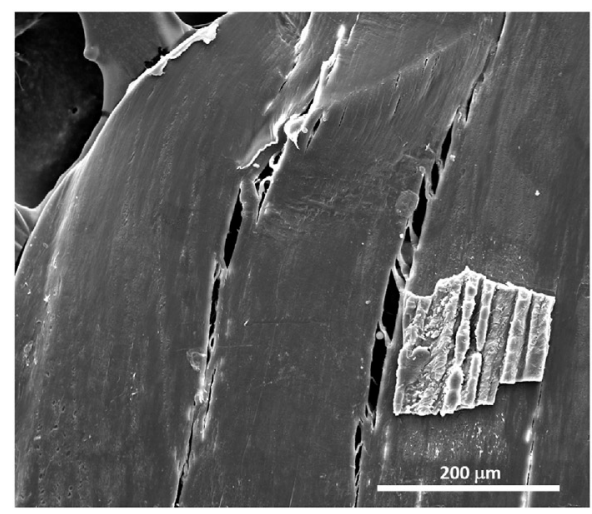

(b)

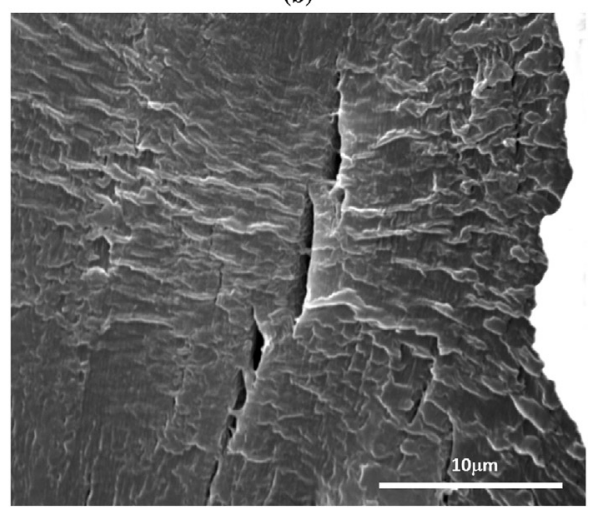

(d)


Smaller voids. SEM observations with secondary electrons. 




(a)



(c)

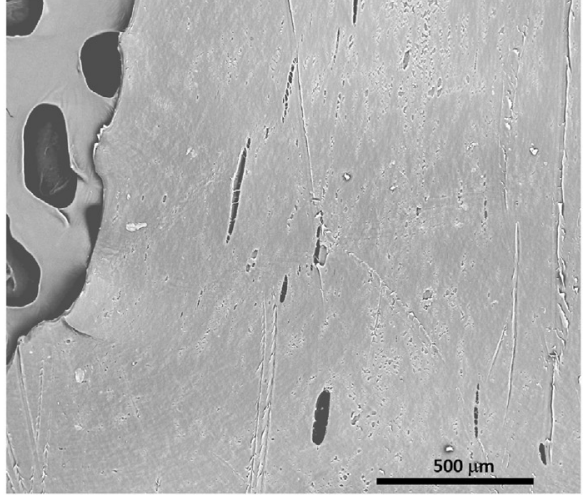

(b)



(d)

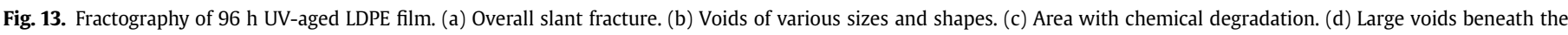
surface. SEM observations with backscattered electrons in Z-contrast mode, except for (c).

outset of radiation (Fig. 4) whereas other physico-chemical characteristics undergo an incubation period and remain unchanged below 48 h of aging; see Fig. 3 for $\mathrm{CI}$ and VI and Fig. 5b for crystallinity. Correspondingly, there are two regimes over which the strain to break $\varepsilon_{\mathrm{b}}$ decreases. In the first (roughly up to $48 \mathrm{~h}$ of radiation), $\varepsilon_{\mathrm{b}}$ goes from $\sim 5$ down to $\sim 2$ without any noticeable change in crystallinity or reaction products, as measured by $\mathrm{CI}$ and VI. In the second regime (beyond $48 \mathrm{~h}$ of aging), $\varepsilon_{\mathrm{b}}$ continues to decrease, albeit less abruptly to $\sim 1$ while $\mathrm{CI}$ and VI undergo a significant increase.

To gain insight into the transient strengthening, our first attempt is to invoke radiation-induced crosslinking and its effect in counteracting chain scission. Indeed, crosslinking generally increases the strength of a semicrystalline polymer by improving the cohesive strength of the amorphous phase due to a higher molar mass [33], or by way of branching and its deterrent effect on chain mobility and disentanglement [6].

A method to estimate the average molecular weight between crosslinks is from mechanical tests above the glass transition temperature. In particular, the evolution of hardening provides great insight. It is worth emphasizing, at this juncture, the importance of obtaining true stress-strain responses in order to make robust estimates of hardening rates. Close examination of Fig. 7b shows a significant increase in hardening rate between the unaged condition and the specimens aged under $48 \mathrm{~h}$. This type of hardening is usually attributed to an increase in crosslinking.

In order to test this hypothesis, the concentrations of chain scissions and crosslink nodes were estimated for each aging condition using GPC measurements as input; see equation (6). The results reported in Fig. 15 clearly show that in the $0 \mathrm{~h}-48 \mathrm{~h}$ range, chain scission dominates over crosslinking.

Difficulties in extracting information about the molecular weight between crosslinks is documented in the literature and the results in Fig. 15 should be interpreted with care. Additionally, the insolubility of sufficiently large, crosslinked structures can impede their analysis with GPC and would not be included in the molecular weight distribution curves, which may also lead to lower estimates of molecular weight averages despite the crosslinking reactions [34].

\subsection{Chemi-crystallization}

Two distinct scenarios of oxidative embrittlement are found in the literature. In the case of a largely predominant chain scission process, the destruction of the entanglement network leads to ductility loss. However, since small macromolecular fragments are also very mobile in a rubbery amorphous phase, they migrate rapidly up to the surface of crystalline lamellae to integrate and thicken them. The increase in both lamellar thickness and crystallinity ratio then explain the increase in yield stress [3]. In the case of a pure crosslinking process, for instance by gamma irradiation in the case of PE, the same mechanical trends are typically observed [35], but with a totally different physico-chemical scenario. Indeed, it appears clearly that branching disfavors cavitation during yielding and is not favorable to ductility. It should be emphasized the strong increase in yield stress $(+25 \%)$ for a small concentration of chemical crosslinks $\approx 10^{-2} \mathrm{~mol} / \mathrm{kg}$, in comparison with the concentration of entanglement crosslinks $\approx 40 \times 10^{-2} \mathrm{~mol} / \mathrm{kg}$ (see Fig. 2 in Ref. [35]).

Neither of these scenarios is applicable to the low density 



Fig. 14. (a) Nominal strain at break versus aging time; (b) (Post mortem) true strain to fracture versus aging time.

polyethylene studied here. Although a chain scission process is predominant, it causes practically no change in the crystallinity ratio or in the thickness of primary lamellae in the early hours of aging (see Figs. 5 and 6). As a consequence, the first scenario cannot be retained. However, crosslinking is not totally negligible because it prevents chemi-crystallization. Indeed, instead of an increase in the thickness of primary lamellae, we observe clearly the formation of secondary lamellae (see Fig. 5). It should be emphasized that, due to its low sensitivity, DSC allows to detect only the largest secondary lamellae. The melting endotherms of thinner lamellae are probably hidden in the decreasing baseline of DSC endotherms (between 20 and $50^{\circ} \mathrm{C}$ ). Therefore, the population of these new small crystals should be far from negligible.

Fig. 6 shows the evolution of lamellar thickness with aging. The thickness of primary crystals remains overall constant during aging while that of secondary crystals, $l_{c}$, reaches a local maximum at $48 \mathrm{~h}$. This results in a higher reduction of the interlamellar space, further restraining chain mobility. When $l_{c}$ reaches a maximum at $48 \mathrm{~h}$ so does the flow stress (Fig. 7a), thus supporting the premise that the transient UV-induced strengthening is a consequence of chemi-crystallization.

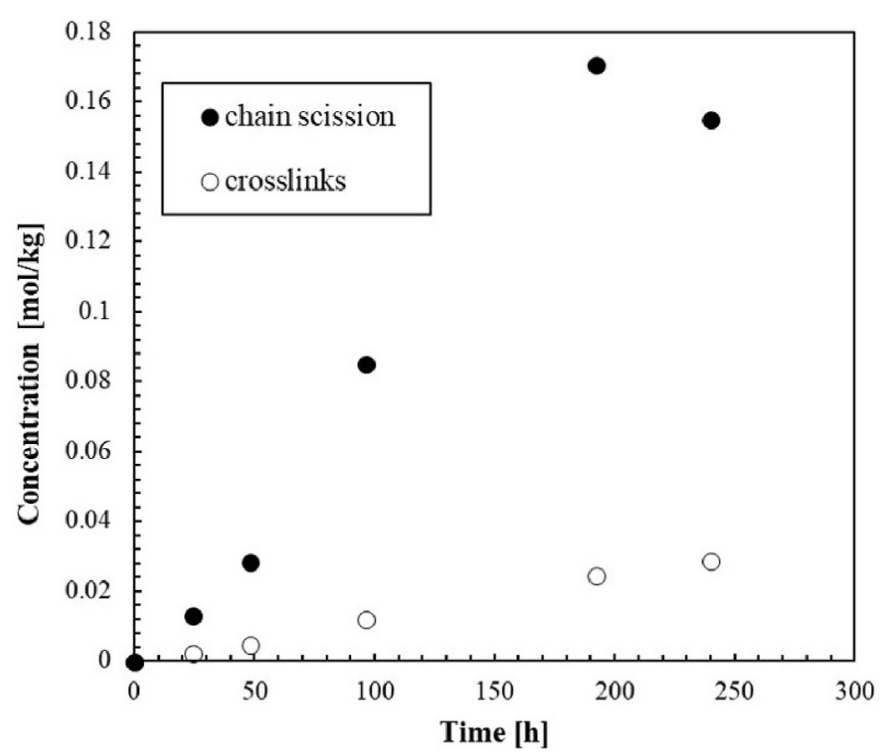

Fig. 15. Number of chain scissions and crosslinks per unit mass as a function of UV aging time.

Given that crosslinking has an important impact on mechanical properties, a new scenario is advanced whereby new small crystals act as chemical crosslinks. The free chain segments generated by chain scission are presumed to crystallize instantly, thus, the expected adverse effect of chain scission on the mechanical response of the material is not observed in the $24-48 \mathrm{~h}$ aging range. The crystallites resulting from chain scission and its consequent chemicrystallization behave like crosslinks, resulting in the observed strengthening at intermediate UV doses. Since the effect of the thin crystallites is similar to an increased entanglement density, they also affect the large strain response of the material [36], as observed in Fig. 7, where the strain hardening increases at intermediate UV doses. The effect of secondary crystals can be synergistic with the concurrent oxidation-induced crosslinking, as estimated in Fig. 15.

Evidently, the translation of the resulting small increase in crystallinity ratio into an equivalent concentration in chemical crosslinks remains a conceptual issue. One way to investigate the validity of this scenario would consist of conducting mechanical tests above the melting point of secondary lamellae. Indeed, the mechanical behavior should remain unchanged between the pristine and aged materials.

As UV radiation increases further ( $48 \mathrm{~h}-96 \mathrm{~h}$ range), the chemicrystallization stops, and thus the adverse effect of chain scission becomes evident, as it becomes all the more dominant (Fig. 15). The overall decrease in the molecular weight (Fig. 4) is such that after $96 \mathrm{~h}$ of exposure it has already decreased by $\sim 70 \%$, from $M_{w}=164.500 \mathrm{~g} / \mathrm{mol}$ to just $M_{w}=47.000 \mathrm{~g} / \mathrm{mol}$. This effectively counteracts any strengthening effect of chain scission (by way of chemi-crystallization) or crosslinking, contributing to the weakening observed in Figs. 7 and 8. The decrease in strain hardening observed beyond $96 \mathrm{~h}$ of aging is attributed to the lower density of network entanglements [36] that results from a lower molecular weight. Moreover, the predominance of chain scission on the later stages of oxidation lead to formation of what we have referred to as "chemical cracks" (see section 3.3), further contributing to the weakening of the material.

\subsection{Chemical stress model}

The transient strengthening effect due to chemi-crystallization 
As Received

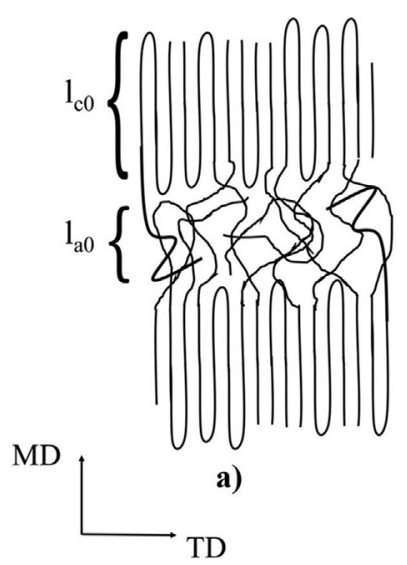

Post UV-Aging (chemi-crystallization)

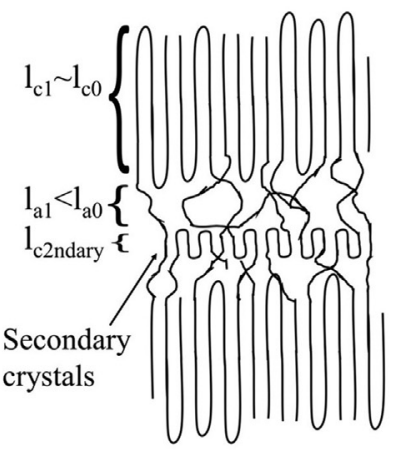

b)
Post UV-Aging

(cracking)

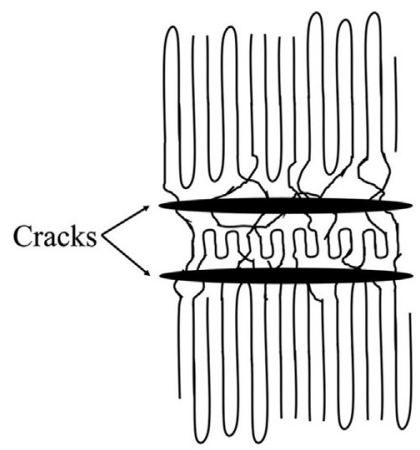

c)

Fig. 16. Schematic scenario of UV-induced cracking in the absence of mechanical loading along the transverse direction (TD) in oriented LDPE films.

contrasts with other phenomena that weaken the polymer response, namely chemical cracking and cavitation. In section 3.3 we showed that photo-oxidation results in cracking in the absence of mechanical loading, with chemical cracks occurring along the transverse direction (TD) (Figs. 9 and 10).

Note that the tensile specimens were cut out from aged films. A question therefore arises as to whether any cracks were induced by cutting. This is unlikely, as punch cutting induces a highly localized shearing deformation. In addition, the majority of cracks were observed away from specimen edges. It is thus not surprising that other investigators have followed the same protocol (aging the films then machining the specimens) [25,34].

The appearance of "chemical cracks" in the absence of mechanical loading can be attributed to a "chemical stress" [37], which is a residual stress related to the chemical reactions of oxidation. This residual stress may have its origin in the volume change concurrent with the thickening of the oxidized layer, or in density gradients due to chemi-crystallization.

The critical stress required for cracking can be estimated by (see Ref. [37]):

$\sigma_{\text {chem }}=\sqrt{\frac{\Gamma E_{s}}{Z h_{c}}}$

where $\Gamma$ is the fracture resistance of the oxidized layer, $E_{S}$ its elastic modulus, $Z$ is a dimensionless parameter that characterizes different cracking patterns [38], and is the thickness of the oxidized layer. Taking $E_{s}=236 \mathrm{MPa}$ from the experiments, $\Gamma=5 \mathrm{KJ} / \mathrm{m}^{2}$ for LDPE [39], and $h_{c}$ as a fraction of the film thickness, say $25 \mu \mathrm{m}$, we obtain a critical chemical stress of $\sim 110 \mathrm{MPa}$ for surface cracking and $150 \mathrm{MPa}$ for channeling. Compared with the flow stress of LDPE, the estimated value for surface cracking is large enough to produce local cracking.

The pattern of these chemical cracks can be explained in terms of the film's orientation and the changes in its morphology. Blown films of semicrystalline polymers develop a preferred orientation during processing [40-42]. For LDPE, the preferred orientation means a row-nucleated lamellar structure consisting of stacks of lamellae aligning along the machine direction (MD) and amorphous zones between the crystalline stacks [40-42], as sketched in Fig. 16a.

The orientation dependence is manifested in the tensile anisotropy of the as-received film (Fig. 9c), where the orientation of the lamellae along MD results in higher flow stress and strain hardening, and lower strain to fracture in comparison with TD. Fig. 16b depicts how the thickness of the interlamellar space $l_{a 0}$ is reduced at least by a factor of 2 as a result of the introduction of new and thin crystallites via chemi-crystallization. The reduction of the interlamellar space leads to embrittlement of PE $[3,6]$ therefore promoting the formation of cracks. The results obtained from DSC for lamellar thickness of primary and secondary crystalline regions (Fig. 6) together with the observed cracking lead us to presume that the new interlamellar thickness $l_{a 1}$ (Fig. 16b), falls below the critical interlamellar thickness established by Fayolle et al. for polyethylene $l_{a c}=6 \mu m[3,6]$, below which a sharp ductile to brittle transition occurs.

Additionally, since oxidation occurs on the amorphous region, it is expected to act specifically in the interlamellar spaces along TD, making them more vulnerable to the formation of cracks, Fig. 16c. Studies of the tear resistance of PE have shown that the low tear resistance along TD of LDPE relative to its linear counterparts (such as HDPE and LLDPE) stems from the low number of tie molecules between lamellar stacks in LDPE. In the case of oxidized LDPE, the advance of the chain scission reactions leads to the decrease of these tie chains, which could make the transverse direction more prone to cracking. These oxidation-induced cracks contribute to the weakening observed at larger UV doses and the observed lower ductility.

\subsection{Chemo-mechanical aspects}

In the previous section, the formation of chemical cracks was rationalized on the basis of a chemical stress concept and their pattern based on processing history combined with radiation induced morphological changes.

In addition, the type of damage observed in mechanically loaded specimens post aging demonstrates other aspects of coupling between chemistry and mechanics in oxidative embrittlement. While extensive damage and cracking were observed in UV-aged film specimens (Figs. 12 and 13) no trace of damage was seen in the highly ductile unaged films; see Fig. 11a.

That no cavitation is observed in the tensile deformation of LDPE is certainly in keeping with the literature [16]. However, the present investigation clearly shows that UV irradiation activates the 




(a)

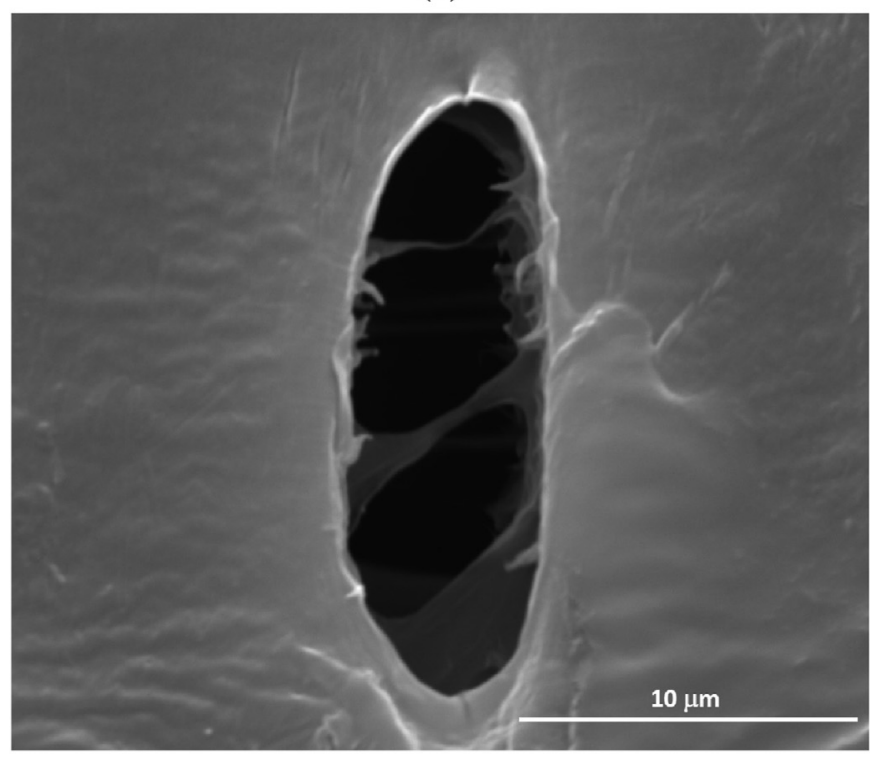

(b)

Fig. 17. SEM micrographs of well developed craze-like voids beneath the fracture of a $96 \mathrm{~h}$ specimen.

cavitation process. To our knowledge, this is the first report of cavitation in UV-exposed LDPE.

The formation of cavities upon deformation in semicrystalline polymers is believed to depend on the relationship between the strength of the crystalline phase and the strength of the amorphous phase: a strong crystalline region and/or weak amorphous phases promote cavitation since these conditions favor the deformation of the amorphous phase over the plastic deformation of crystalline regions [14]. Taking this into account, photo-oxidation presumably promotes the observed cavitation by: i) providing nucleation sites for voids since it creates surface defects and chemical cracks as observed in the post-aging micrographs (Figs. 9 and 10); ii) forming secondary crystals which increase the stress necessary for the deformation of crystalline regions (Fig. 6), and; iii) reducing the molecular weight, thus weakening the amorphous region by decreasing its density of entanglements (Fig. 4).

Our observations in UV irradiated LDPE reveal the formation of cavities at multiple scales and in various shapes. Some rather large elongated, probably coalesced micro-cracks were shown in Figs. 12 and 13. Fig. 17 shows instances of smaller craze-like voids in the $96 \mathrm{~h} \mathrm{UV}$ aged specimen. The presence of various void sizes hints at a continuous void formation process.

Interestingly, the "chemical cracks" observed in heavily irradiated films are oriented along the transverse direction (Fig. 10) whereas the mechanically induced ones are mostly parallel to the loading (machine) direction (Figs. 12 and 13). Recall that films with the type of chemical cracks in Fig. 10 had essentially zero ductility. On the other hand, for moderately irradiated films, cavities are favored by profuse chain scissions then grow plastically upon further drawing and align themselves with the loading direction. Some of the elongated cavities are several hundreds of microns long as a result of coalescence in "columns".

The absence of cavitation damage does not prevent failure in the pristine films, but the latter is induced by some macroscopic shear band, as manifested in the slant fracture mode in Fig. 11. In aged specimens, the terminal event also seems to be a (macro) shear band although both chemical and mechanical damage must play a role in causing premature instability.

It is worth noting in closing that the chemically induced damage leads, through cavitation, to dilatation and probably pressure sensitivity of plastic flow. Indeed, the tensile deformation of aged LDPE films is not volume-preserving, contrary to what has been claimed in the literature for LDPE and other low crystallinity polymers [16].

\section{Conclusions}

Chemo-mechanical aspects of oxidative embrittlement have been investigated in low-density polyethylene using an unprecedented combination of physico-chemical and mechanical property characterization. This has enabled new phenomena to be uncovered, namely: (i) transient strengthening, (ii) chemical cracking, and (iii) radiation-induced cavitation, thus shedding new light on the complex phenomena involved at multiple length scales.

- Transient strengthening manifests in the increase in both the flow stress and strain hardening capacity of the polymer at low to moderate radiation doses. This was explained by chemicrystallization, which leads to the formation of thin crystallites that play the role of chemical crosslinks. At higher radiation doses, chain scission dominates and the usual weakening ensues.

- Photo-oxidation leads to the formation of micro-cracks in the absence of any mechanical loads. The cracks appear oriented along the transverse direction of the films. A superficial layer embrittlement model is invoked to rationalize these "chemical cracks" by means of a residual stress termed "chemical stress" akin the thermal stress in multi-layered systems.

- The tensile deformation of aged films is not volume preserving. Voids and long cracks form parallel to the loading direction, in contrast with the behavior of pristine LDPE. Photo-oxidation presumably promotes cavitation by providing nucleation sites generated by chain scission events.

- The processes involved in the (photon-mediated) oxidative embrittlement of semicrystalline polymers are likely to borrow many aspects of the specific mechanisms pertaining to lowdensity polyethylene, as uncovered in this investigation. Cavitation, for instance is expected to play an even bigger role in materials with higher crystallinity. 


\section{Declaration of competing interest}

The authors declare that they have no known competing financial interests or personal relationships that could have appeared to influence the work reported in this paper.

\section{CRediT authorship contribution statement}

A.K. Rodriguez: Investigation, Writing - original draft, Visualization. B. Mansoor: Methodology, Resources, Supervision, Project administration. G. Ayoub: Conceptualization, Methodology, Funding acquisition. X. Colin: Conceptualization, Methodology, Formal analysis, Writing - review \& editing. A.A. Benzerga: Conceptualization, Formal analysis, Writing - review \& editing, Supervision, Project administration, Funding acquisition.

\section{Acknowledgment}

This research is possible by the NPRP award (NPRP 7-1562-2571) from the Qatar National Research Fund (a member of The Qatar Foundation). The statements made herein are solely the responsibility of the authors. Special thanks to the Qatar Petrochemical Company (QAPCO) for providing the film materials of the study and for fruitful discussions with Dr. Mabrouk Ouederni.

\section{References}

[1] A.L. Andrady, A. Torikai, H.H. Redhwi, K.K. Pandey, P. Gies, Consequences of stratospheric ozone depletion and climate change on the use of materials, Photochem. Photobiol. Sci. Off. J. Eur. 14 (1) (2014) 170-184.

[2] J.F. Rabek, Photodegradation of Polymers: Physical Characteristics and Applications, Springer, Berlin, 1996.

[3] B. Fayolle, E. Richaud, X. Colin, J. Verdu, Review: degradation-induced embrittlement in semi-crystalline polymers having their amorphous phase in rubbery state, J. Mater. Sci. 43 (22) (2008) 6999-7012.

[4] Y.-C. Hsu, M.P. Weir, R.W. Truss, C.J. Garvey, T.M. Nicholson, P.J. Halley, A fundamental study on photo-oxidative degradation of linear low density polyethylene films at embrittlement, Polymer 53 (12) (2012) 2385-2393.

[5] V.H. Rolón-Garrido, M. Kruse, M.H. Wagner, Size exclusion chromatography of photo-oxidated LDPE by triple detection and its relation to rheological behavior, Polym. Degrad. Stabil. 111 (2015) 46-54.

[6] B. Fayolle, X. Colin, L. Audouin, J. Verdu, Mechanism of degradation induced embrittlement in polyethylene, Polym. Degrad. Stabil. 92 (2) (2007) 231-238.

[7] I. Craig, J. White, P.C. Kin, Crystallization and chemi-crystallization of recycled photo-degraded polypropylene, Polymer 46 (2) (2005) 505-512.

[8] B. Wunderlich, Thermal Analysis of Polymeric Materials, Springer Science \& Business Media, 2005.

[9] P. Gijsman, G. Meijers, G. Vitarelli, Comparison of the UV-degradation chemistry of polypropylene, polyethylene, polyamide 6 and polybutylene terephthalate, Polym. Degrad. Stabil. 65 (3) (1999) 433-441.

[10] T. Corrales, F. Catalina, C. Peinado, N.S. Allen, E. Fontan, Photooxidative and thermal degradation of polyethylenes: interrelationship by chemiluminescence, thermal gravimetric analysis and FTIR data, J. Photochem. Photobiol. Chem. 147 (3) (2002) 213-224.

[11] M. Gardette, A. Perthue, J.L. Gardette, T. Janecska, E. Földes, B. Pukánszky, S. Therias, Photo- and thermal-oxidation of polyethylene: comparison of mechanisms and influence of unsaturation content, Polym. Degrad. Stabil. 98 (11) (2013) 2383-2390.

[12] C. El Mazry, Durability Of Innovative Valve Products in Polyamide 6,6. Theses, Ecole nationale supérieure d'arts et métiers - ENSAM, 2013.

[13] A. Galeski, Strength and toughness of crystalline polymer systems, Prog. Polym. Sci. 28 (12) (2003) 1643-1699.

[14] A. Pawlak, A. Galeski, A. Rozanski, Cavitation during deformation of semicrystalline polymers, Prog. Polym. Sci. 39 (5) (2014) 921-958.

[15] S. Humbert, O. Lame, J.M. Chenal, C. Rochas, G. Vigier, New insight on initiation of cavitation in semicrystalline polymers: in-situ SAXS measurements, Macromolecules 43 (17) (2010) 7212-7221.

[16] A. Pawlak, Cavitation during tensile deformation of high-density polyethylene, Polymer 291 (48) (2007) 1397-1409.

[17] L. Laiarinandrasana, T.F. Morgeneyer, H. Proudhon, C. Regrain, Damage of semicrystalline polyamide 6 assessed by 3D X-ray tomography: from microstructural evolution to constitutive modeling, J. Polym. Sci., Part B: Polym. Phys. 48 (13) (2010) 1516-1525.

[18] T.F. Morgeneyer, H. Proudhon, P. Cloetens, W. Ludwig, Q Roirand, L. Laiarinandrasana, E. Maire, Nanovoid morphology and distribution in deformed HDPE studied by magnified synchrotron radiation holotomography Polymer 55 (25) (2014) 6439-6443.

[19] ASTM G-154 standard practice for operating fluorescent ultraviolet (UV) lamp apparatus for exposure of nonmetallic materials, ASTM Int. 44 (2011) 5-10, 0

[20] J.F. Rabek, Polymer Photodegradation: Mechanisms and Experimenta Methods, Springer, Berlin, 1995.

[21] M. Da Cruz, L. Van Schoors, K. Benzarti, X. Colin, Thermo-oxidative degradation of additive free polyethylene. Part I. Analysis of chemical modifications at molecular and macromolecular scales, J. Appl. Polym. Sci. 133 (18) (2016 43287.

[22] D.W. Van Krevelen, Properties of Polymers, Elsevier, Amsterdam, 1990, 86 236, 465, 597, 792.

23] G. Ayoub, F. Zaïri, M. Naït-Abdelaziz, J.M. Gloaguen, Modelling large deformation behaviour under loading-unloading of semicrystalline polymers: application to a high density polyethylene, Int. J. Plast. 26 (3) (2010) 329-347.

[24] X. Poulain, L.W. Kohlman, W. Binienda, G.D. Roberts, R.K. Goldberg, A.A. Benzerga, Determination of the intrinsic behavior of polymers using digital image correlation combined with video-monitored testing, Int. J. Solid Struct. 50 (11-12) (2013) 1869-1878.

[25] I. Grigoriadou, K.M. Paraskevopoulos, K. Chrissafis, E. Pavlidou, T.G. Stamkopoulos, D. Bikiaris, Effect of different nanoparticles on HDPE UV stability, Polym. Degrad. Stabil. 96 (1) (2011) 151-163.

[26] H. Lobo, J.V. Bonilla, Handbook of Plastics Analysis, Marcel Dekker, 2003.

[27] P. Dilara, D. Briassoulis, Degradation and stabilization of low-density polyethylene films used as greenhouse covering materials, J. Agric. Eng. Res. 76 (4) (2000) 309-321.

[28] F. Severini, R. Gallo, S. Ipsale, Some aspects of the environmental photodegradation of LDPE, Polym. Degrad. Stabil. 22 (1) (1988) 53-61.

[29] S. Girois, L. Audouin, J. Verdu, P. Delprat, G. Marot, Molecular weight changes during the photooxidation of isotactic polypropylene, Polym. Degrad. Stabil. 51 (2) (1996) 125-132.

[30] D. Briassoulis, A. Aristopoulou, M. Bonora, I. Verlodt, Degradation characterisation of agricultural low-density polyethylene films, Biosyst. Eng. 88 (2) (2004) 131-143.

[31] A. Pineau, A.A. Benzerga, T. Pardoen, Failure of metals I. Brittle and ductile fracture, Acta Mater. 107 (2016) 424-483.

[32] M.M. Qayyum, J.R. White, Plastic fracture in weathered polymers 28 (3) (1987) 469-476.

[33] G.H. Michler, F.B. Calleja, Mechanical Properties of Polymers Based on Nanostructure and Morphology, Taylor \& Francis, 2005

34] E. Miyagawa, K. Tokumitsu, A. Tanaka, K. hei Nitta, Mechanical property an molecular weight distribution changes with photo- and chemical-degradation on LDPE films, Polym. Degrad. Stabil. 92 (10) (1956) 1948, 2007.

[35] X. Colin, C. Monchy-Leroy, J. Verdu, Effect of gamma irradiation on tensile properties of low molecular weight polyethylene samples, Radiat. Phys. Chem. 80 (8) (2011) 895-901.

[36] Bernard A.G. Schrauwen, Roel P.M. Janssen, Leon E. Govaert, H.E.H. Meijer Intrinsic deformation behavior of semicrystalline polymers, Macromolecules 37 (aug 2004) 6069-6078.

[37] K.N. Cundiff, Y. Madi, A.A. Benzerga, "Photo-oxidation of semicrystalline polymers: damage nucleation versus growth, Polymer 188 (2020) 122090.

[38] J. Hutchinson, Z. Suo, "Mixed Mode Cracking in Layered Materials," Vol. 29 of Advances In Applied Mechanics, Elsevier, 1991, pp. 63-191.

[39] H. Kausch, Polymer Fracture. Polymers - Properties and Applications, Springe Berlin Heidelberg, 2012

[40] X. Zhang, S. Elkoun, A. Ajji, M. Huneault, Oriented structure and anisotropy properties of polymer blown films: HDPE, LLDPE and LDPE, Polymer 45 (1) (2004) 217-229.

[41] L-B.W. Lee, R.A. Register, D.M. Dean, Tear anisotropy in films blown from polyethylenes of different macromolecular architectures, J. Polym. Sci., Part B: Polym. Phys. 43 (4) (2005) 413-420.

[42] R.H. Somani, L. Yang, L. Zhu, B.S. Hsiao, Flow-induced shish-kebab precurso structures in entangled polymer melts, Polymer 46 (20) (2005) 8587-8623. 